\title{
Econometric Analysis of the Development of Economic Entities in the Sphere of Small Business
}

\author{
Ulugmurodova Nodira Berdimurodovna
}

\begin{abstract}
In this article the factors that affect the development of small business entities in the region's economy and determination the relationship between them through correlation-regression analysis as well as directions of development of social and labor relations in the enterprises of the industry are identified.
\end{abstract}

\section{INTRODUCTION}

Encouragement of the small business and private entrepreneurship in our republic is one of the essential, strategic factors of socio-economic development of the country. The small business creates conditions for the expansion of employment and the increasing of the income of the population, eliminates the possible conflicts between the social groups and forms a favorable social environment. In this context, the special attention to the development of small business and private entrepreneurship is being paid in our republic. The issue of development of small business and private entrepreneurship is considered as a strategic task of the economic policy of our state.

From this point of view, "Creation of favorable business environment for the development of small business and private entrepreneurship, serious prevention of illegal interference by state, law enforcement and supervisory authorities in the activities of business structures" [6] has been determined as an vital task in the Strategy of Actions for the Further Development of the Republic of Uzbekistan in the five priority areas for 2017-2021.

Econometric analysis of the development of economic entities in the sphere of small business allows determining the strength of complex relation socio-economic phenomena by means of economic and mathematical methods, identifying existing laws and conducting experimental research on them.

\section{LITERATURE REVIEW}

A. Abdullaev A.M., Djamalov M.S. Econometrics-2. Textbook for Higher education - T.: 2011. P. 612

In this textbook has been expressed the factors on the construction of econometric models and the calculation link of multicollinearity, issues on econometric modeling, and correlation and regression analysis methods.
In addition, periodic rows of research, dispersion, correlation and factorial analysis methods and various aspects have been characterized and the methods of constructing the system of econometric equations used in the interpretation of the results of econometric research, dynamic econometric models, and expert assessment methods have been studied.

\section{B. Magnus Ya.R., Katyshev P.K., Peresetskiy A.A. \\ Econometrics. Textbook. - M., 2005. - P.499.}

This work investigated methods of constructing econometric models, connection between factors, correlation and regression analysis. Moreover, it has been studied the techniques of periodic rows, dispersion, correlation and factor analysis and various aspects of dynamic econometric models and expert assessment methods.

C. Ivanova M.A. Economic statistics. Textbook. - M.,

INFRA, 2000. P.210

This textbook highlights the methods of constructing econometric models, correlation and regression analysis methods. In addition, periodic rows of research, dispersion, correlation and factorial analysis methods and various aspects have been characterized and the methods of constructing the system of econometric equations used in the interpretation of the results of econometric research, dynamic econometric models, and expert assessment methods have been studied.

D. Andrew F., Siegel. Statistics - practical business. 4th edition, Moscow: Williams Publishing House, 2002. P.389-450

In this work peculiarities of economic systems which are considered in econometric models, using the least squares method in the processing of economic information, correlation, dispersion, factor analysis methods and the system of econometric equations are investigated.

\section{RESEARCH METHODOLOGY}

In the course of the investigation, dialectical and systemic approach, comparative and contrastive analysis methods, statistical and dynamic approach, and regression and correlation analysis were used in the study the economic systems and rates of economic development economic entities in the sphere of small businesses. 
In the present day, a large number of software products have been created in order to accelerate the process of implementing these methods and to select an essential model of analysis. We carried out the following analysis using SPSS software package.

\section{ANALYSIS AND RESULTS}

While conducting research we studied the scientific works of scientists like Abdullayev A.M., Djamalov M.S. [2], Ya.R.Magnus [3], M.Ivanova [4], Andrew F. Siegel [5] while evaluating the development of small business entities activities and working out a model of forecasting. They have worked out prospective methods based on developed econometric analysis, i.e., methods of correlation-regression analysis and they worked on their improvement.

As a result of the analysis of the development of small business entities by correlation-regression analysis methods, it is determined to determine the strength of the connection amongst the factors, and to develop social-labor relations in the industries of the field, and finally will be determined the directions for achieving labor productivity. The most important step in the strategy of the model is to select the econometric expression describing the dependence of the predicted indicator on selected factors.

If the scale of the development of the activities of the subjects of small business is clear and complete, the level of management and efficiency of its operation will be so high.

According to the calculations of scientists in our country, "there are more than 100 intuitive and formalized methods of promoting economic and social events, and 15-20 of them are used regularly in applied research." Subjective thinking and predictions are reflected in intuitive methods. They do not envisage the use of mathematical-statistical methods and tools. Therefore, the level of data acquired is in line with the actual condition of the object being investigated is low. The practical significance of these methods in the development of management decisions will not be significant enough.

At the moment identifying key factors that influence the development of small business entities by using correlation-regression methods, predicting their development prospects by creating multi-factor regression models is an urgent problem.

The research begins with the identification of all the factors affecting the development of the subjects of small business and choosing the most important of them using correlation-regression methods.

In order to create econometric model of development of subjects of small business in Samarkand region the following factors were selected:

Table 1: Factors influencing the volume of gross product created in the small business sectors in Samarkand region

Result: the volume of gross product created in the small business sector, UZS billion. UZ - Y

\begin{tabular}{|l|c|}
\hline \multicolumn{1}{|c|}{ Factors } & Character \\
\hline $\begin{array}{l}\text { share of small business and private entrepreneurship in } \\
\text { GRP, } \%\end{array}$ & $\boldsymbol{X}_{\boldsymbol{I}}$ \\
\hline average tax load on small businesses, \% & $\boldsymbol{X}_{\mathbf{2}}$ \\
\hline Refinancing rate set by the Central Bank, $\%$ & $\boldsymbol{X}_{\mathbf{3}}$ \\
\hline $\begin{array}{l}\text { Investments into fixed capital in the sectors of the economy } \\
\text { (UZS bn.) }\end{array}$ & $\boldsymbol{X}_{\mathbf{5}}$ \\
\hline Number of operating small businesses, units; & $\boldsymbol{X}_{\boldsymbol{6}}$ \\
\hline $\begin{array}{l}\text { The volume of small business in fixed capital investments, } \\
\text { UZS billion }\end{array}$ & $\boldsymbol{X}_{\boldsymbol{7}}$ \\
\hline $\begin{array}{l}\text { those employed in small entrepreneurship, (thousand } \\
\text { people) }\end{array}$ & $\boldsymbol{X}_{\boldsymbol{8}}$ \\
\hline labor productivity in small business, (thousand soums) & $\boldsymbol{X}_{\mathbf{9}}$ \\
\hline Price index (inflation), (\%) & $\boldsymbol{X}_{\mathbf{1 0}}$ \\
\hline $\begin{array}{l}\text { Export volumes of small businesses sectors, (million. } \\
\text { USD) }\end{array}$ & \\
\hline
\end{tabular}

The factors influencing the development of the econometric model of small business sectors developments in the Samarkand Region were selected (Table 1). Correlation-regression analysis methods can be used to determine the effect of these factors on the resulted factor. This is determined by calculating the pair correlation coefficients. This method gives us opportunity not to add factors that are duplicating and weakly linked to the resultant factor into the constructed econometric model.

Table 2: Values of factors included in the correlation-regression analysis

\begin{tabular}{|c|c|c|c|c|c|c|c|c|c|c|c|}
\hline & $\mathbf{Y}(\mathbf{t})$ & $X_{1}$ & $X_{2}$ & $X_{3}$ & $X_{4}$ & $X_{5}$ & $X_{6}$ & $X_{7}$ & $X_{8}$ & $X_{9}$ & $X_{10}$ \\
\hline 2005 & 577,3 & 49,9 & 22,6 & 16,0 & 203,5 & 9666 & 73,3 & 738,6 & 781,6 & 7,8 & 34,4 \\
\hline 2006 & 996,9 & 64,2 & 22,4 & 16,0 & 233,4 & 10495 & 95,4 & 797,7 & 1249,7 & 6,8 & 73,9 \\
\hline 2007 & 1336,2 & 66,4 & 22,4 & 14,0 & 305,5 & 11605 & 119,1 & 864,2 & 1546,2 & 6,8 & 128,9 \\
\hline 2008 & 1718,1 & 68,8 & 22,1 & 14,0 & 403,7 & 10288 & 152,2 & 921,6 & 1864,3 & 7,8 & 90,8 \\
\hline 2009 & 2138,3 & 71,2 & 22,0 & 14,0 & 551,4 & 10626 & 177,0 & 961,9 & 2223,0 & 7,4 & 110,8 \\
\hline 2010 & 2925,1 & 73,6 & 21,9 & 14,0 & 934,2 & 10689 & 362,8 & 1009,0 & 2899,0 & 7,3 & 66,6 \\
\hline 2011 & 3771,1 & 76,2 & 21,8 & 12,0 & 1145,2 & 12517 & 568,8 & 1045,5 & 3607,0 & 7,2 & 97,8 \\
\hline 2012 & 4795,3 & 75,9 & 21,6 & 12,0 & 1383,3 & 11117 & 702,7 & 1075,1 & 4460,3 & 7,0 & 96,2 \\
\hline 2013 & 6153,9 & 77,1 & 21,6 & 12,0 & 1914,9 & 12648 & 923,1 & 1129,2 & 5449,8 & 6,8 & 215,5 \\
\hline 2014 & 7119,3 & 77,4 & 21,6 & 10,0 & 2247,8 & 12860 & 1293,0 & 1174,3 & 6062,6 & 6,1 & 213,7 \\
\hline 2015 & 8762,8 & 77,9 & 21,5 & 9,0 & 2854,0 & 13840 & 1297,1 & 1213,9 & 7218,7 & 5,6 & 272,5 \\
\hline 2016 & 11737,0 & 78,0 & 21,4 & 9,0 & 3321,4 & 13981 & 1315,5 & 1254,6 & 9355,2 & 5,7 & 278,2 \\
\hline 2017 & 14325,8 & 78,2 & 21,3 & 14,0 & 3307,1 & 16005 & 1356,2 & 1298,7 & 11030,9 & 14,4 & 295,4 \\
\hline
\end{tabular}

Then a multi-factor econometric model will be formed by using correlation-regression methods. Multi-factor correlation-regression analysis is used in order to determine the econometric model of factor dependence. The following econometric model (multi-factor regression equation) was used to analyze the development of small business sector in the Samarkand region:
1) $y=\beta_{0}+\sum_{i=1}^{m} \beta_{i} x_{i}$ 
Linear model;

Here,

$\beta_{0}$ - free limit;

$y$ - employment level of graduates;

$x_{i}$ - Factors influencing the employment level of graduates;

$\beta_{i}$ - multi - factor model parameters; $(i=1,2,3 \ldots . \mathrm{m})$;

$m$ - Number of selected factors.

The given $y=f\left(x_{1}, x_{2}, \ldots ., x_{n}\right)$ must be found. We use the method small squares to determine this connection.

\begin{tabular}{|c|c|c|}
\hline № & Name & Expression \\
\hline 1. & Constant, free limit & $\beta 0$ \\
\hline 2. & $\begin{array}{l}\text { Multi-factor } \\
\text { correlation coefficient }\end{array}$ & $\mathrm{R}^{2}$ \\
\hline 3. & $\begin{array}{l}\text { Uncertain parameters } \\
\text { of multiple factor } \\
\text { regressions }\end{array}$ & $\beta 1, \beta 2, \ldots \beta \mathrm{k}$ \\
\hline 4. & $\begin{array}{l}\text { The standard error of } \\
\text { the evaluation }\end{array}$ & $\begin{array}{l}\text { the model becomes so } \\
\text { important if the value is } \\
\text { small }\end{array}$ \\
\hline 5. & $\begin{array}{l}\text { Determination } \\
\text { coefficient }\end{array}$ & $\begin{array}{l}\text { If the value is about } 1 \text {, the } \\
\text { model considered adequate }\end{array}$ \\
\hline 6. & F-Fischer's coefficient & $\begin{array}{l}\text { If } F_{\text {хақ }}>F_{\text {табл }} \text { the coefficient } \\
\text { of determining is significant }\end{array}$ \\
\hline 7. & P-Value & $\begin{array}{l}\text { (Criterion indicating the } \\
\text { importance of "zero" } \\
\text { hypothesis) model less than } \\
0.05 \text { is considered as a } \\
\text { significant model }\end{array}$ \\
\hline
\end{tabular}

The peculiarity of multi-factor correlation connections is that, in its regression equation, several important and substantial factors are involved. Right choice of the most significant among these factors and their introduction into the regression equation has a great importance. It is based on the choice of factors and the qualitative theoretical analysis and it will be conducted in three stages. At the first stage (in the initial analysis) factors are selected without any terms. In the second step, they are analyzed using the pair correlation coefficients. In order to this, the matrix of the pair correlation coefficients between the symbols $\mathrm{y}_{1}, \mathrm{x}_{1}, \mathrm{x}_{2}, \ldots, \mathrm{x}_{\mathrm{n}}$ is formed. In the third stage of the factor analysis, the regression equation is determined and whether its parameters are characteristic or not, are evaluated by special measure.

Correlation analysis methods can be used to determine the effect of these factors on the resultant character. Here, the pair correlation coefficient is defined as follows:

$$
r_{i j}=\frac{\left(\sum x_{i} x_{j}-\sum x_{i} \times \sum x_{j} / n\right)}{\sqrt{\left(\sum x_{i}^{2}-\left(\sum x_{i}\right)^{2} / n\right)\left(\sum x_{j}{ }^{2}-\left(\sum x_{j}\right)^{2} / n\right)}}
$$

In order to determine which factors should be included in the regression equation, we construct pair correlation coefficients between the factors (Table 4).

\begin{tabular}{|l|l|l|l|l|l|l|l|l|l|l|l|}
\hline & \multicolumn{1}{|c|}{$Y(t)$} & $X 1$ & $X 2$ & $X 3$ & $X 4$ & $X 5$ & $X 6$ & $X 7$ & $X 8$ & $X 9$ & $X 10$ \\
\hline $\mathrm{Y}(\mathrm{t})$ & 1,00 & & & & & & & & & & \\
\hline $\mathrm{X} 1$ & 0,69 & 1,00 & & & & & & & & & \\
\hline $\mathrm{X} 2$ & $-0,88$ & $-0,91$ & 1,00 & & & & & & & \\
\hline $\mathrm{X} 3$ & $-0,62$ & $-0,74$ & 0,76 & 1,00 & & & & & & \\
\hline $\mathrm{X} 4$ & 0,98 & 0,73 & $-0,91$ & $-0,75$ & 1,00 & & & & & \\
\hline $\mathrm{X} 5$ & 0,94 & 0,70 & $-0,82$ & $-0,59$ & 0,92 & 1,00 & & & & & \\
\hline $\mathrm{X} 6$ & 0,93 & 0,75 & $-0,91$ & $-0,80$ & 0,98 & 0,89 & 1,00 & & & \\
\hline $\mathrm{X} 7$ & 0,93 & 0,89 & $-0,98$ & $-0,78$ & 0,95 & 0,89 & 0,95 & 1,00 & & & \\
\hline $\mathrm{X} 8$ & 1,00 & 0,72 & $-0,90$ & $-0,65$ & 0,98 & 0,94 & 0,94 & 0,95 & 1,00 & & \\
\hline $\mathrm{X} 9$ & 0,40 & 0,04 & $-0,19$ & 0,41 & 0,21 & 0,41 & 0,14 & 0,21 & 0,37 & 1,00 & \\
\hline $\mathrm{X} 10$ & 0,92 & 0,68 & $-0,80$ & $-0,70$ & 0,93 & 0,93 & 0,91 & 0,88 & 0,92 & 0,20 & 1,00 \\
\hline
\end{tabular}

$\mathrm{r}_{\mathrm{ij}} \boldsymbol{x}_{\boldsymbol{i}}$ and $\boldsymbol{x}_{\boldsymbol{j}}$ in the table are the pair correlation coefficient between the factors. It is known that, in the multi-factor regression equation, strongly correlated correlation factors should not be interconnected simultaneously ${ }^{1}$. As can be seen in Table 4 , some factors' mutual $\left(\mathrm{z}_{\mathrm{i}}\right.$ and $\left.\mathrm{z}_{\mathrm{j}}\right)$ pair correlation coefficient $\left(r_{i j}\right)$ is less than its critical value for absolute value, i.e. $\left|r_{i j}\right|<\mathrm{r}_{\mathrm{kr} .}$. Therefore, four from all factors were planned to be included in the econometric model, here as a critical value of correlation coefficient is taken as $r_{k r}=0,91$.
If we analyze the above table, we will see that there are strong interconnected factors that are larger $r_{k r}$ than critical values. Therefore, we found to deduce factors from the regression equation the factors $\mathrm{x}_{2}, \mathrm{x}_{4}, \mathrm{x}_{7}, \mathrm{x}_{8} \mathrm{Ba} \mathrm{x}_{10}$, and $\mathrm{x}_{9}$ factors from $\left|r_{Y x_{i}}\right| \geq 0,5$ weakly connected to $Y$. 
The most important stage in the analysis of socio-economic development by using correlation-regression analysis is the choice of the econometric expression describing the dependence of the resultant indicator on selected factors. Quality, significance and reliability of the formed econometric expression are assessed on the basis of the following criteria:

1) The overall quality of the econometric model is evaluated by the multi-factor correlation coefficient and the coefficient of determinism;

2) The importance of econometric models will be assessed using the Fisher criterion and the error of approximation;

3) The importance of the econometric model parameters is evaluated using the St'yudent criterion.

In determining the general quality of the defined regression equation, the coefficient of determinability $\left(\mathrm{R}^{2}\right)$ is calculated using the following formula:

$$
R^{2}=1-\frac{\sum_{i=1}^{n}\left(y_{i}-\hat{y}_{i}\right)^{2}}{\sum_{i=1}^{n}\left(y_{i}-\bar{y}\right)^{2}}
$$

$y_{i}$ - The observed number of the resultant indicator;

$y$-average arithmetic value of the resultant indicator;

$\hat{y}$-Detected, forecasted, leveled number of the resultant indicator;

$\mathrm{n}$ - Number of observations.

The model which is determined the determinant coefficient i.e. shows the share of the resultant variable dispersion that is explained by the influence of the factors being considered. This value includes values between " 0 " and "1". The closer it is to the value of " 1 ," the factors that are included in the regression equation justify the action of the resulting indicator.

An analysis of the significance of the identified model is carried out by checking as "the hypothesis of equal to zero ". "The hypothesis of equal to zero" is expressed as $H_{0}: \beta_{1}{ }^{\prime}=\beta_{2}{ }^{\prime}=\ldots=\beta_{k}{ }^{\prime}=0$ refers to the general value of the regression coefficient. If the results of the analysis do not deny the "The hypothesis of equal to zero", in that case it can be concluded as: factors $x_{1}, x_{2}, \ldots, x_{k}$ affect to the resultant indicator " $y$ " is not significant and the overall quality of the regression equation is low", The "hypothesis of equal to zero " is checked by using a dispersion analysis, and the "hypothesis of equal to zero " $\mathrm{H}_{0}: \mathrm{D}_{\text {fact }}=\mathrm{D}_{\text {residue }}$ is alternative hypothesis expresses as $\mathrm{H}_{1}: \mathrm{D}_{\text {fact }}=\mathrm{D}_{\text {residue. The F-Fisher }}$ criterion is used to check these hypotheses.

The real value of the criterion is determined by the following formula:

$F=\frac{\sum_{i=1}^{n}\left(\hat{y}_{i}-\bar{y}\right)^{2} / k}{\sum_{i=1}^{n}\left(y_{i}-\hat{y}_{i}\right)^{2} /(n-k-1)}=\frac{R^{2}}{1-R^{2}} * \frac{(n-k-1)}{k}$

(4) Here:

$\sum_{i=1}^{n}\left(\hat{y}_{i}-\bar{y}\right)^{2} / k-$ Factor dispersion corresponding to one level of liberty (number of degrees of liberty $\gamma 1=\mathrm{k}$ );

$$
\sum_{i=1}^{n}\left(y_{i}-\hat{y}_{i}\right)^{2} /(n-k-1) \quad-\quad \text { residual dispersion }
$$

corresponding to one degree of liberty (number of degrees of freedom $\gamma 1=\mathrm{n}-\mathrm{k}-1$ );

$\mathrm{n}$ - number of observations;

$\mathrm{k}$ - number of factors (parameters) in multi-factor regression equation.

The actual value of the F-Fisher criterion $\left(\mathrm{F}_{\text {real }}\right)$ will be compared with the value of the criterion $\left(\mathrm{F}_{\text {table }}(\alpha ; k ; n-k-1)\right)$. If $F_{\text {real }}>F_{\text {table }}$ in that case determined model is defined as significant.

The actual value of the F-Fisher criterion $\mathrm{F}_{\text {real }}=35,014$ was calculated in the model developed by analyzing the factors affecting the gross product volume of small businesses in the Samarkand region (see Table ). As well as, when the number of liberty level was $\gamma 1=4$ according to the numerator and according to the denominator was $\gamma 2=8$, the table value of the F-Fisher criterion (significance ratio $\mathrm{p}=0.95$ ) was $\mathrm{F}_{\text {table }}=$ 3.84. Thus, our multi-factor regression equation is significant (Table 5).

Table 5: Criteria for controlling the quality and importance of the model

\begin{tabular}{|c|c|c|c|c|c|}
\hline $\begin{array}{c}\text { Multi-factor } \\
\text { correlation } \\
\text { coefficient } \\
\text { R }\end{array}$ & $\begin{array}{c}\text { Multi factor } \\
\text { determinant } \\
\text { coefficient } \\
\text { R-square }\end{array}$ & $\begin{array}{c}\text { Corrected } \\
\text { R-square }\end{array}$ & $\begin{array}{c}\text { The standard } \\
\text { error of } \\
\text { assessment }\end{array}$ & F-real & P-value \\
\hline 0,973 & 0,946 & 0,919 & 1235,56121 & 35,014 & $4,07 * 10^{-5}$ \\
\hline
\end{tabular}

The importance of the individual parameters of multi-factor regression in the analysis is evaluated using the criteria of St'yudent (T-statistics). The real value of the criterion is determined by the following formula:

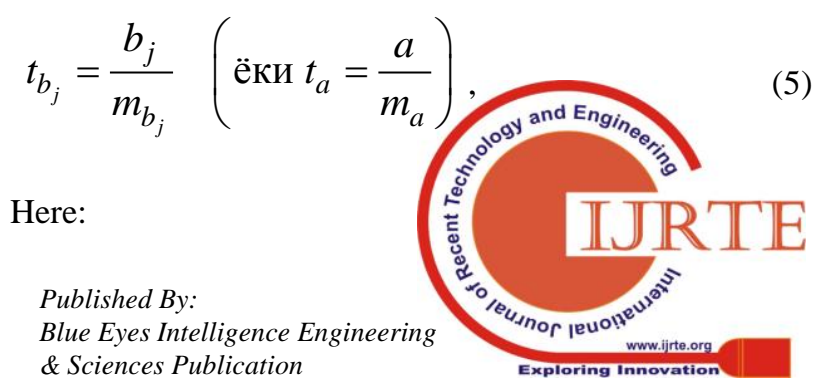


bj (a) - regression coefficients (parameters);

$m_{b j}\left(m_{a j}\right)-$ this is $b j(a)$ the standard error of the parameter

Critical point for the T-statistics St'yudent distribution defined through the expression 5 for the relevant parameters of the regression equation is compared with $t(\alpha ; n-k-1)$.

If a $|t|>\mathrm{t}(\alpha ; n-p-1)$, the parameter is significant, and the "hypothesis of equal to zero" is expressed as $H_{0}: b_{j}=0$ or $H_{0}: a=0$ is rejected.

Additionally, the significance of the parameters of the regression equation can be evaluated by the following simple comparative analysis:

Table 6: Significant factors included in the linear regression model

\begin{tabular}{|c|c|c|c|c|c|}
\hline & \multicolumn{2}{|c|}{ Non-standardized coefficients } & Standardized coefficients & \multirow{2}{*}{ t-measure } & P- quantity \\
\cline { 2 - 4 } & $\mathrm{B}$ & Standard error & Beta & & \\
\hline (Constanta) & $-16588,546$ & 7180,815 & & $-2,310$ & 0,050 \\
\hline $\mathbf{X}_{\mathbf{1}}$ & 6,535 & 74,357 & 0,012 & 0,088 & 0,932 \\
\hline $\mathbf{X}_{\mathbf{3}}$ & $-402,135$ & 314,045 & 0,218 & 1,281 & 0,236 \\
\hline $\mathbf{X}_{\mathbf{5}}$ & 1,020 & 0,498 & 0,429 & 2,049 & 0,075 \\
\hline $\mathbf{X}_{\mathbf{6}}$ & 5,897 & 2,209 & 0,716 & 2,669 & 0,028 \\
\hline
\end{tabular}

Thus, the factors included in the regression equation are of high significant, significant, relatively significant, and insignificant. Based on the results of the analysis, we have underlined the high significant and significant factors included in our model (Table 6).

Developed linear regression model has the following appearance:

$Y=-16588,546+6,535 \times X_{1}+402,35 \times X_{3}+1,020 \times X_{5}+5$, $897 \times X_{6}$,

\section{CONCLUSION AND RECOMMENDATIONS}

Thus, according to the final reflections the effects of factors as "the volume of gross product created in the small business sector" is "share of small business and private entrepreneurship in GRP,\%", "refinancing rate set by the Central Bank,\%", "number of operating small businesses, units", "the volume of small business in fixed capital investments, UZS billion" are significant. The effect of these factors on the resulted indication can be explained by the following:

1. Increase in the share of small business and private entrepreneurship in GRP $\left(\mathrm{X}_{1}\right)$ by $1.0 \%$ will result in increase of gross output in small business by $6.535 \%$;

2. Increase in the refinancing rate $\left(X_{3}\right)$ established by the Central Bank by one percent will result in a decrease in the volume of gross output created in the small business sector to 402.135 million soums;

3. The increase in the number of operating small business subjects $\left(X_{5}\right)$ by one percent will lead to a $1,020 \%$ increase in the volume of gross domestic product created by small businesses;

4. Increase in the volume of small business $\left(\mathrm{X}_{6}\right)$ in fixed capital investments by one percent will result in an increase in the volume of gross product created in the small business sector by $5,897 \%$.

With the help of the econometric model described above $(2$...), we have compiled the list of perspective models for the
- If it is $|t| \leq 1$, the coefficient of regression is statistically insignificant;

- If it is $1<|t| \leq 2$, the regression coefficient is statistically significant;

- If it is $2<|t| \leq 3$, the regression coefficient is statistically significant;

- If it is $|t|>3$, the regression coefficient is statistically significant. This idea applies in cases $(n-p-1)>20$ and $\alpha \geq 0,05$.

$\mathrm{X}_{1}, \mathrm{X}_{3}, \mathrm{X}_{5}$, and $\mathbf{X}_{\mathbf{6}}$ factors influencing the volume of gross domestic product created by the use of statistical data in Samarkand region for 2005-2017.

\section{REFERENCES}

[1] Abdullayev Yo., General Theory of Statistics, T. Fan, P.240, 1993.

[2] Abdullaev A.M., Djamalov M.S. Econometrics-2. Textbook for Higher education - T., P. 612, 2011

[3] Magnus Ya.R., Katyshev P.K., Peresetskiy A.A., Econometrics, Textbook. - M., P.499, 2005.

[4] Ivanova M.A., Economic statistics, Textbook, M., INFRA, P.210, 2000.

[5] Andrew F., Siegel, Statistics - practical business, 4th edition, Moscow: Williams Publishing House, P.389-450, 2002.

[6] Decree of the President of the Republic of Uzbekistan, "On the strategy for further development of the Republic of Uzbekistan”, on February 7 , 2017, PD-4947, Appendix1, paragraph 3.4.

[7] Annual Statistical collection of the Republic of Uzbekistan. Statistical collection for 2007-2016. 